
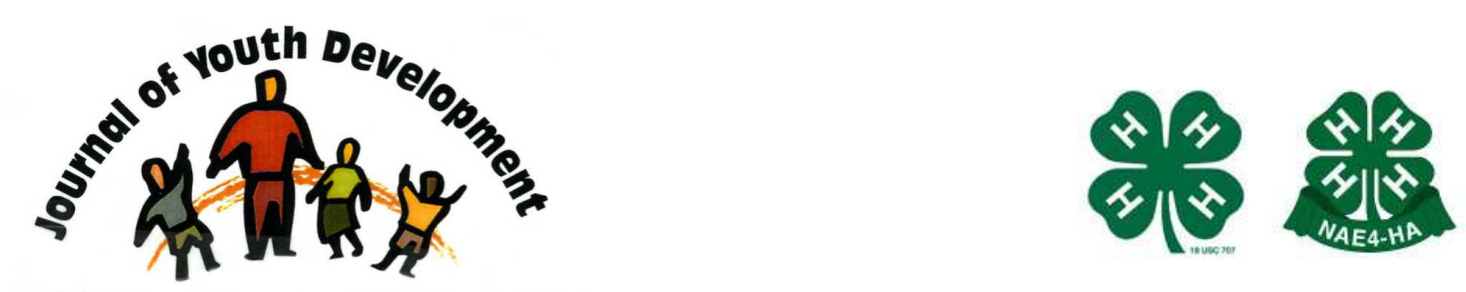

Bridging Research \& Practice

\title{
The Respite and Recreation: An Innovative Recreation Service to Adopted Children with Special Needs
}

Heewon Yang

Department of Health Education and Recreation Management Southern Illinois University

hyang@siu.edu

Jennifer M. Howard

Department of Health Education and Recreation Management

Southern Illinois University

jmhoward@siu.edu 


\title{
JOURNAL OF YOUTH DEVELOPMENT \\ bridging research and practice

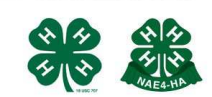

Volume 1, Number 3, Winter 2006-2007

Article 0603PA006

\section{The Respite and Recreation: An Innovative Recreation Service to Adopted Children with Special Needs}

\author{
Heewon Yang and Jennifer M. Howard \\ Southern Illinois University
}

\begin{abstract}
Often youth in the foster care system have traumatic experiences associated with abuse and separation from their biological family. These experiences may lead to emotional, psychological, and behavioral problems that challenge the new adoptive family dynamic. This article introduces the Respite and Recreation ( $R$ \& $R$ ) program in a Midwestern area. R \& R combines faculty, staff, and graduate students from a local University, local community resources, and staff from a local adoption agency to provide recreation, respite, and professional support services for children with special needs and their adoptive parents. The R \& R program provides the adopted children with structured recreation programs for their growth, the parents with a break from stress, and volunteer students with opportunities to incorporate their academic learning into real life situations. Service learning programs such as the $R \& R$ also provide university faculty with excellent opportunities to conduct action research.
\end{abstract}

It is reported that there are currently more than 120,000 children in the U.S. foster care system who are awaiting adoption (Monroe, 2006). Since 1987, the number of annual adoptions has remained relatively constant, ranging from 118,000 to 127,000 . However, supportive systems for adoptive families in the U.S. have increased since the government sponsored initiatives such as the Adoption and Safe Families Act of 1997 and President Clinton's Adoption 2000. Although this increase in supportive systems for adoptive families may be laudable, it is reported that insufficient attention is being devoted to ensuring that adoptions are sustained over time and that the quality of adoptive home environments is suitable to each child's long-term developmental needs (Howard \& Smith, 1997).

Most adopted children in foster care system typically experienced a variety of injustices such as abuse and neglect during their formative years, and some may not have experienced any consistent, caring, or trusting human relationships (Lashua, et al., 2000). In addition, the trauma associated with abuse, separation from the biological family, and participation in the child welfare system results in varying degrees of emotional, psychological, and behavioral 
problems (Groze, 1994). According to Gil (1991), children who are removed from their parents' custody as a result of sexual, physical, emotional abuse and/or neglect typically exhibit common signs, including: anxiety; depression; difficulties in school; anger; inappropriate sexual behavior; delinquency; low self-esteem; and compulsivity.

Therefore, while adopting a child may be a positive experience for most families, not all adoptions are successful, and some children do develop severe emotional and behavioral difficulties that need treatment (Modell, 2000). In particular, the issues and difficulties experienced by adopted older children or adolescents make the adoptive adjustment process more difficult (Stolley, 1993). More specifically, although the recent statistics are not available, $10 \%$ to $20 \%$ of adoptions of children aged three and older disrupt (Barth \& Berry, 1990).

\section{Recreation Based Support Programs}

One of the effective ways to help adopted children deal with their difficulties may be to provide recreation-based supportive programs. In general, the recreation-based programs help children enhance their developmental skills and provide psychological, emotional, social, and physical benefits. The impact of the psychological and emotional benefits of recreation activities include:

- increased self-esteem (Li \& Moore, 1998),

- self-awareness and sense of identity (Mobily, 1992),

- autonomy, independence, self-direction, and self-expression (Larson \& Kleiber, 1992),

- $\quad$ self-consistency and positive self-regard (Haggard \& Williams, 1992).

Recreation based support programs promote communication skills (Grotevant \& Cooper, 1986), social skills (Dattilo \& Murphy, 1991), and establishment of supportive friendship network (Cotterell, 1996; Kandel, 1978). Recreation programs also provide physiological benefits such as improvement in cardiovascular health, health maintenance, coordination, flexibility, weight control, muscular strength, and conditioning (Wells \& Hooker, 1990).

Respite for adoptive parents is a service crucial to successful adoption because these programs can provide adoptive parents with much-needed rest, recuperation, and readjustment. For example, according to Keck and Kupecky's study (1995), adoptive parents identify respite as an extremely valuable service by allowing them to recharge their batteries. Another study (Kramer \& Huston, 1999) also indicated that respite programs (and respite providers) were among the most helpful informal resources for providing family stability.

Although respite programs for adoptive parents are now in progress across the country, many adoptive families are still denied respite care simply because the resources are underdeveloped or nonexistent (Lashua, Widmer, \& Munson, 2000). As a result, it may be very beneficial for recreation service providers and adoption service providers to work together to facilitate quality supportive services for adoptive families. For example, the recreation programs for adoptive families can be provided by a collaborative effort of academic program at a local university (e.g., recreation, youth development, family studies, and other human service areas) and staff at adoption and foster care services. 


\section{The Respite and Recreation ( R \& R) Program}

The R \& R program was developed as a way to provide unique services for both adopted children with special needs and their adoptive parents. The R \& R program combines professional support services traditionally available to adoptive families (e.g., through adoption agencies) with nontraditional (recreation-based) support networks of adoptive children, adoptive parents, university student volunteers, and faculty.

\section{Program Goals and Objectives}

Two primary goals of the $\mathrm{R} \& \mathrm{R}$ program were:

- to reduce the likelihood of adoption disruption for families of children with special needs by providing respite for the parents through the provision of therapeutic recreation services for the children; and

- to provide a structured therapeutic recreation program to help adopted children to develop necessary skills to satisfy their needs.

The Respite and Recreation program focused on the following three objectives:

- developing two respite and recreation program areas to support adoptive families of children with special needs,

- designing respite and recreation programs to meet the needs of each child, and

- providing training with the opportunity to integrate theory and practice for university students.

\section{Program Structure}

The two program areas developed for the R \& R program included a facility-based, daylong (Saturday) recreational respite and a facility-based weekend overnight recreational respite. Each program offered sports, art programs, and integrated social skills training that provided a variety of activities to impact participant development. The facility-based, daylong, recreational respite was provided at the recreational facilities at a local university (e.g., classrooms, swimming pool, rock climbing, skate arena, gym, ropes course facility, etc.) and at other regional recreation and leisure facilities (e.g., parks, museum, ice tubing, theater, science center, local farm, etc.). These daylong programs occurred between 10:00 A.M. and 5:00 P.M. Parents were notified of the meeting gathering places in advance to drop and pick up their children. This type of respite and recreation program was offered approximately once every three to four weeks. The activities of the daylong program included initiative and social cooperative activities, ropes courses, arts and crafts, drama, outdoor education, a variety of games and sports, and field trips to local parks and recreation facilities. At the end of each day, the participants were provided an opportunity to evaluate the program and to reflect on the experience on that day.

Weekend facility-based respite and recreation programs were provided at established camps in the area. During these programs, the children spent two days at a local camp. The weekend respite and recreation programs also provided the children with a wide range of recreational activities, such as horseback riding, ropes courses, recreation and sports, arts and crafts, hiking, environmental education, anger management skills, cooking, movie night, and campfire. Examples of programs for the first day are ice-breakers, social skills training, and movie night, night hiking, and camp fire. For the second day, team building and problem solving activities in 
the morning, and outdoor challenging activities such as hiking, ropes course, canoeing are typically provided.

The 1:1 staff and children ratio was maintained for both program areas. At the end of each program, times for reflection and evaluation were provided both for children and staff.

\section{Service Learning and the R \& R Partnership Model}

The Respite and Recreation ( $\&$ \& ) was grounded in Service Learning theory (Dewey, 1934). Service learning is an organized learning experience through collaborative interagency partnership. This interagency partnership maximizes limited resources of academic institutions, community agency, and other community resources. In particular, service learning allows students to apply classroom learning to real world situations, to reflect on their experiences, and to develop a sense of caring for others.

Figure 1 (the R \& R Partnership Model, Yang 2004) illustrates the roles and the relationships among the entities associated with the $R \& R$ program. The Respite and Recreation program is a community-based recreation participation program that primarily involves three types of community organizations - an adoption service agency, a local university, and various community facilities and resources. Each entity plays a unique role, and is an essential component for the success of the program. For instance, staff members at a local adoption service assist the program in the following areas:

- program advertisement through their monthly newsletter, mailing out program flyers, and word of mouth,

- participants registration,

- budgeting,

- fund raising (e.g., grant writing),

- program follow-up (e.g., satisfaction survey).

Staff at a local university are primarily responsible for program planning, implementation, and evaluations. However, another very crucial role of the university staff is recruiting student volunteers and providing orientation programs. In most cases, the recruitment of a sufficient number of volunteer students who are motivated and well-trained is essential for the successful provision of a program. University staff are also involved in program advertisement, participant registration, budgeting, fund raising, and program follow-up.

Lastly, faculty and graduate students who are involved in the program process have great opportunities to conduct empirical research studies. Examples of research studies that have been conducted through the R \& R are "Examination of Psycho-Social Characteristics of Adopted Children," "Recreational Needs Assessment of Adopted Children," "Socio-Behavioral Characteristics of Adopted Children," "R \& R Program Evaluation," etc.

In addition, community facilities and resources such as local camps, parks and recreation, museums, science centers, university recreation and sport facilities have been great assets to utilize. Many times, they provided their facilities for free or offered discounted group rates for the participants.

The Respite and Recreation ( $R \& R$ ) program was originally funded by the U.S. Department of Health and Human Services. After the grant from the U.S. Department of Health and Human Services expired, revenue was secured by grants from local charities such as LPGA (Ladies 
Professional Golf Association), Demitri Foundation, a graduate assistantship from the university department, and program fees from the participants.

Figure 1.

The Respite and Recreation Partnership Model

(Modified from The Respite and Recreation Collaboration Model, Yang, 2004).

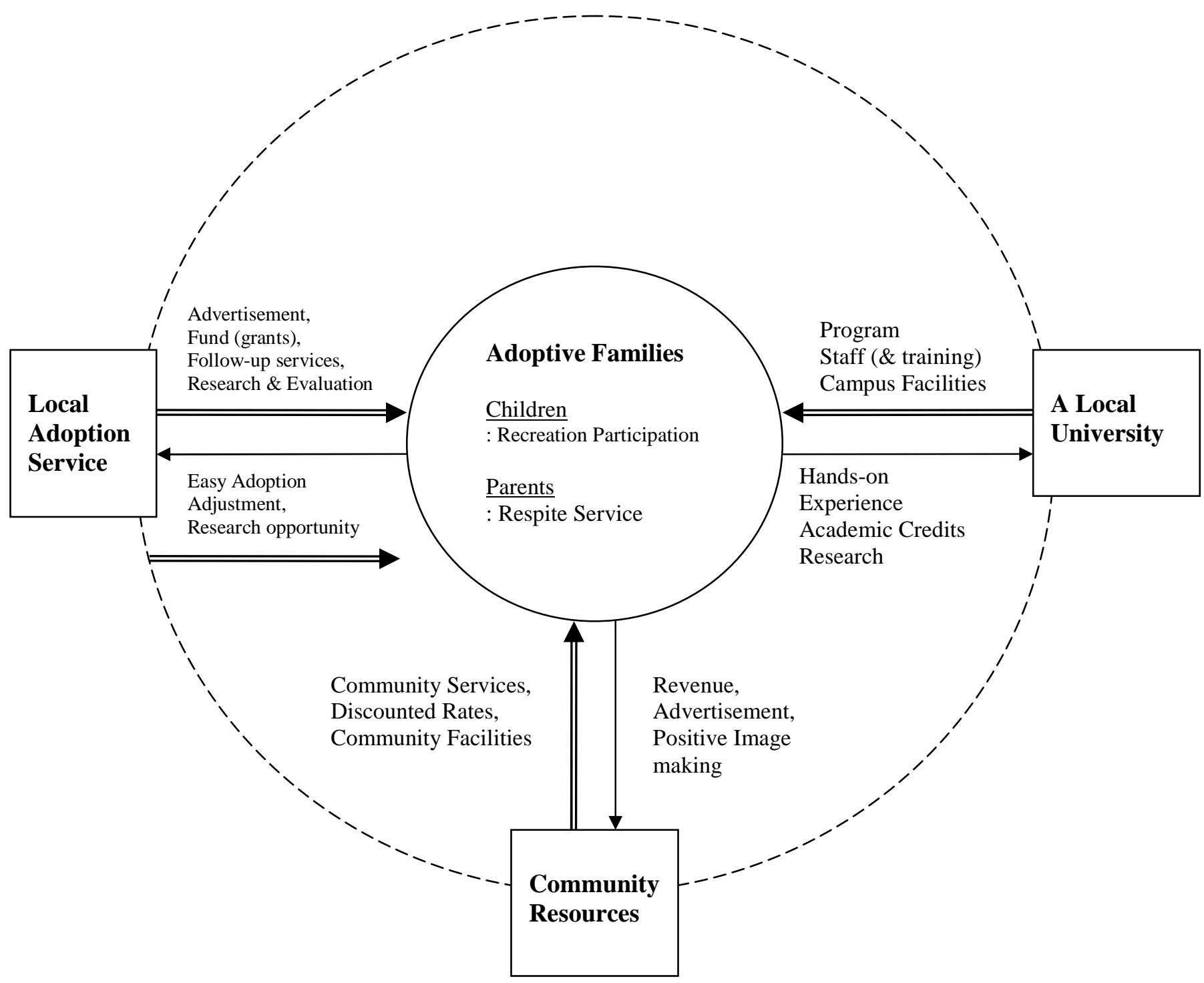

Note: $\Longrightarrow$ : What you provide : What you receive 


\section{Development and Process of Respite and Recreation Programs}

The first step in the Respite and Recreation ( $\& R$ ) program occurred upon the referral of children by a local adoption agency. Prior to the actual program delivery, frequent meetings were made among university and the adoption agency staff. The profiles and contact information were obtained in advance and at the university, student volunteers were recruited and a series of volunteer training programs were offered.

The $\mathrm{R} \& \mathrm{R}$ programs were primarily designed, implemented, and evaluated by the program director (i.e., faculty in recreation department), the program supervisor (a graduate assistant), and student volunteers for the program. Needs assessment of each child was conducted through gathering information from the parents, from the staff at a local adoption services, through direct contact with the parents by phone, and through interviews and surveys on the spot. The results of the need assessment were used as the basis for developing the respite and recreation programs. Although needs varied from child to child, most of the participants demonstrated poor social skills. Therefore, the program's primary goals focused on social skills development such as peer socialization, friendship development, trust building, communication skills, and impulse control and anger management.

The program outcomes were measured through daily progress notes that documented each child's conduct in regard to affective/emotional behavior, and social interaction between other participants, staff, and their families. Semi-structured interviews with participants and their parents resulted in positive feedback that describe significant emotional and behavioral progress, improved social interaction with both adults and children, and increased physical participation. According to the ongoing formative evaluation, parents highly rated the communication and quality of the staff, the quality of the facilities, the respite duration, the wide variety of activities, and the overall enthusiasm of their child.

\section{Conclusion and Implications}

The $\mathrm{R} \& \mathrm{R}$ program is an effective provision of respite and recreation services to adoptive families. The R \& R is a collaborative and interdisciplinary effort to better serve adoptive families in our communities. According to Monroe (2006), there are more than 500,000 children in the U.S. foster-care system and around 120,000 are being adopted each year. Respite care is one area in which opportunity will continue to grow.

The Respite and Recreation ( $R \& R$ ) program can provide important benefits to the families of adopted children with special needs. First, the children participate in therapeutic recreation programs designed to promote social skills, to enhance leisure skills and knowledge, and to increase self-esteem and self-competence. In particular, children adopted under special needs (e.g., abused, old age, disabilities, negligence, drugs, etc.) would require more specialized care from qualified program providers. The R \& R program introduced in this article included adopted children who have been sexually abused. Parents of the children reported that the R \& R program helped a lot for the development of their children (Yang, 2004).

Second, the parents receive a break from the stress associated with caring for their adopted children. Adoptive parents need to recoup their strength to continue fulfilling their care giving responsibilities. The respite program demonstrates success in reducing family stress, improving 
parents' ability to attend to their own health needs, and to maintain their employment (Family Support Services, 2006).

Third, the program can be a valuable experience for student volunteers by enabling them to incorporate their academic learning into real life situations. Students will have opportunities to reflect their learning, develop a sense of caring for other people, and grow responsible citizens in our community.

Finally, service learning programs such as the $R \& R$ provide university faculty with excellent opportunities to conduct action research. For example, descriptive studies that examine the characteristics of the program participants (e.g., physical, cognitive, social, and affective domain), intervention studies (e.g., development of intervention programs, program outcome studies), and measurement studies (e.g., changes in the participant growth and development through the program) can be feasibly conducted. Also, examining the educational benefits accruing to volunteers, such as attitude changes toward children with special needs and the development of direct leadership skills, can be a fruitful line of future research.

\section{References}

Barth, R. P. \& Berry, M. (1988). Adoption and disruption: rates, risks, and responses. Hawthorne, NY: Adline de Gruyter.

Cotterell, J. (1996). Social networks and social influences in adolescence. London: Routledge.

Dewey, J. (1934). Experience and education. New York: Collier Books.

Datillo, J., Murphy, W. (1991). Leisure education program planning: A systematic approach. State College, PA: Venture Publishing, Inc.

Family Support Services (2006). Respite program. Retrieved November 4, 2006, from http://www.fssba-oak.org/programs/Respite.htm

Gil, E. (1991). The healing power of play: Working with abused children. New York, NY: The Guilford Press.

Grotevant, H. D., \& Cooper, C. R. (1986). Individuation in family relationships. Human Development, 29, 82-100.

Groze, V. (1994). Clinical and non-clinical adoptive families of special needs children. Families in Society: The Journal of Contemporary Human Services, 75(2), 90-94.

Haggard, L. M., \& Williams, D. R. (1992). Identity affirmation through leisure activities: Leisure symbols of the self. Journal of Leisure Research, 24(1), 1-18.

Howard, J. A., \& Smith, S. L. (1997). Strengthening adoptive families: A synthesis of post-legal adoption opportunities grants. Normal, IL: Illinois State University.

Kandel, D.B. (1978). Homophily, selection and socialization in adolescent friendships. American Journal of Sociology, 84,427-36. 
Keck, G. C. \& Kupecky, R. M (1995). Adopting the hurt child: Hope for families with specialneeds kids. Colorado Springs, CO: Pinon Press.

Kramer, L. \& Houston, D. (1999). Hope for the children: A community-based approach to supporting families who adopt children with special needs.

Larson, R., \& Kleiber, D. A. (1992). Daily experience of adolescents. In P. H. Tolan, \& B. J. Cohler (Eds.), Handbook of clinical research and practice with adolescents (pp. 125-145). New York: John Wiley \& Sons, Inc.

Lashua, B. D., Widmer, M. A., \& Munson, W. W. (2000, May). Some well-deserved "R \& R." Parks and Recreation, 35(5), 56-63.

Li, L., \& Moore, D. (1998). Acceptance of disability and its correlates. The Journal of Social Psychology, 138, 1, 13-25.

Mobily. K. E. (1992). Leisure, lifestyle, and life span. In M. L. Teague \& R. D. MacNeil (Eds.), Aging and leisure: Vitality in later life (pp. 179-206). Dubuque, IA: Brown \& Benchmark.

Modell, M. (2000). Children's adjustment to adoption: Developmental and clinical issues. Family Practice, 17(1), 94.

Monroe, M. (2006, November). Fostering care. First Things, the Journal of Religion, Culture, and Public Life, 2-3.

Stolley, K. S. (1993). Statistics on adoption in the United States. The Future of Children: Adoption, 3(1), 26-42.

Yang, H. (2004). The Respite and Recreation Program: An innovative therapeutic recreation program for children with special needs. Expanding Horizons in Therapeutic Recreation.22, 1623.

Wells, C. L., \& Hooker, S. P. (1990). The spinal injured athlete. Adapted Physical Activity Quarterly, 73$), 265-285$.

(C) Copyright of Journal of Youth Development Bridging Research and Practice. Content may not be copied or emailed to multiple sites or posted to a listserv without copyright holder's express written permission. Contact Editor at: patricia.dawson@oregonstate.edu for details. However, users may print, download or email articles for individual use.

ISSN 2325-4009 (Print); ISSN 2325-4017 (Online) 